\title{
ESTUDIO ICONOGRÁFICO Y GEOMÉTRICO DEL VITRAL DE SAN JOSÉ EN LA CATEDRAL DE CÚCUTA
}

\section{ICONOGRAPHIC AND GEOMETRIC STUDY OF THE STAINED-GLASS WINDOW OF SAN JOSÉ IN THE CATHEDRAL OF CÚCUTA}

\section{Mawency Vergel Ortega ${ }^{1}$}

Julio Alfredo Delgado Rojas²

Yannette Díaz Umaña ${ }^{3}$

Universidad Francisco de Paula Santander -

Cúcuta

1 Doctora en Educación. Postdoctora en Imaginarios y representaciones sociales. Filiación: Universidad Francisco de Paula Santander. Correo electrónico: mawency@ufps. edu.co. Orcid: https://orcid.org/0000-0001-82852968

2 Magister en Educación Matemática, Arquitecto. Filiación: Universidad Francisco de Paula Santander. Correo electrónico: julioalfredo@ufps.edu.co Orcid: https://orcid.org/00000001-6944-832X

$3 \quad$ Magister en Gestión Urbana,Arquitecta. Filiación: Universidad Francisco de Paula Santander. Correo electrónico: yannettedu@ufps.edu.co Orcid: https://orcid.org/ 0000-0003-45821593

\section{RESUMEN}

El artículo tuvo como objetivo analizar el vitral de San José en la Catedral de Cúcuta,-Colombia desde la perspectiva iconográfica y geométrica, teniendo en cuenta la relación con la arquitectura del templo. Se realiza un estudio histórico descriptivo que permite analizar las cualidades geométricas del arte vitral de San José, los cuales confieren al espacio arquitectónico de la catedral recursos perceptuales, simbologías religiosas, e instrumentos que permiten pensar 
en la luz como un componente esencial, cuantificable y calificable.

PALABRAS CLAVE: geometría, arte vitral, historia y arquitectura.

\section{ABSTRACT}

This article aimed to analyze the stained glass window of San José in the Cathedral of Cúcuta-Colombia, from an iconographic and geometric perspective, taking into account the relationship with the temple's architecture. This article is part of the "Arquimatso" strategy that seeks integration between the disciplines of mathematics and architecture to strengthen historical and architectural studies. From there, a descriptive study is carried out to analyze the geometric qualities of the stained glass art of San Jose, which give the cathedral's architectural space perceptual resources, religious symbols, and instruments that allow us to think of light as an essential, quantifiable and qualifiable.

KEY WORDS: geometry, stained glass art, history and architecture

\section{INTRODUCCIÓN}

La investigación de carácter histórico, forma parte de la estrategia "Arquimatso" 4 integra disciplinas de la matemática y la arquitectura para fortalecer los estudios históricos y arquitectónicos. En la investigación realizada por la Universidad Francisco de Paula Santander entorno a la Catedral de San José de Cúcuta ubicada en la zona de frontera entre Colombia y Venezuela, se suman elementos que por sí mismos, darían espacio a mas indagaciones exhaustivas referentes a cada manifestación arquitectónica, artística y tecnológica, es el caso del arte vitral, en el cual se identificaron 60

$4 \quad$ Arquimatso, nace como estrategia que fusiona experiencias investigativas para la enseñanza de la Arquitectura a través de la historia, las matemáticas y la estadística. Esta estrategia vincula el departamento de matemáticas con el departamento de Arquitectura, Diseño y urbanismo de la Universidad Francisco de Paula Santander. piezas, entre las cuales se incorporan escenas bíblicas, ángeles, santos, la imagen del sagrado corazón de Jesús, inmaculado corazón de María, y un San José.

Conviene subrayar, ante todo, la participación del arte vitral en la arquitectura, desde el siglo XVII, y su posterior esplendor en el gótico. En este periodo, el aporte del arte vitral, permitió evidenciar avances tecnológicos en la arquitectura, demostrando la habilidad de reducir los apoyos de la estructura, argumentado por De Fusco (1981), posibilitando abrir vanos en los muros, para dejar pasar la luz tamizada a través de los vidrios de colores. Así mismo, a partir de este fenómeno lumínico transformar los espacios imprimiéndoles espiritualidad, misticismo con esencia románica y paleocristiana.

De ahí que el vitral accedió a jugar con la luz al interior de arquitectura sagrada, no solo en el sentido espacial, sino también metafórico. De tal manera que impacta directamente a los fieles en su forma de percibir el espacio de formas variadas dependiendo la intensidad de la luz, como también advertir su capacidad pedagógica y didáctica como lo menciona Díaz, Vergel, Delgado (2020)

En efecto, el arte vitral se relaciona entonces, directamente con los avances tecnológicos constructivos de la edad media, de la modernidad y los cambios conciliares que se dieron en la iglesia católica, buscando una mayor comprensión y participación de los fieles en la celebración litúrgica como lo refiere Delgado, Díaz, \& Vergel, (2018). Por lo tanto, su naturaleza artística y no estructural de la arquitectura, supera su propia materialidad limitante y trasciende protagónicamente sobre el espacio próximo, a través de la luz filtrada, de ahí su verdadero valor patrimonial. 


\section{METODO}

La investigación se desarrolla dentro del enfoque cualitativo, histórico, y se apoya en analisis cuantativos en torno a geometrias existentes en el vitral de San José de la catedral de San José de cúcuta en Colombia, ubicado en la nave central, fachada principal de la catedral, da su cara visible al coro de la Catedral, se establecen tres categorías de análisis, la primera a partir de los aspectos arquitectónicos de su ubicación y características artísticas, la segunda relacionada con el análisis iconográfico, y la tercera basada en el análisis geométrico.

En cuanto a la primera categoría de los aspectos arquitectónicos de su ubicación y características artísticas, se parte de la noción de Blondel, Callias, y Chaussée, (1986) que argumentan el vitral como un conjunto de trozos de vidrio con características especiales, integradas entre sí por una trama de plomo. El levantamiento se llevó a cabo inicialmente con método directo, con la colaboración de un grupo de trabajo de ocho personas, de tal modo que fuesen cuatro grupos de trabajo, dos grupos encargados de toma de dimensiones (uno interior y otro exterior) usando herramientas como flexómetros y altímetros, y dos grupos, encargados de registro de medidas. Se inició con ubicación del vitral a partir de elaboración de planos de la iglesia. Un segundo metodo incluye el comprobar las dimensiones por triangulación, alturas parciales $\mathrm{y}$ totales (levantamiento altimétrico $\mathrm{y}$ volumétrico). un tercer método fotogramétrico, hace uso de fotogramas captados con cámaras de lentes de alta calidad, tomados desde ciertos puntos de vista perspécticos, para luego, con la ayuda de un ordenador, convertir imagen con líneas de fuga paralelas, es decir, alzados totalmente perpendiculares al punto de vista. Se tomaron luego medidas parciales con longitudes representativas mayores a los dos metros y se usaron sobre los fotogramas.
El análisis iconográfico sigue tres fases, una primera parte textual que explica las características generales del vitral san José, objeto en estudio dentro de marcos teóricos específicos (componentes históricos y estilísticos del origen y de las formas del monumento patrimonial en estudio respectivamente), y que termina con varios aportes originales sobre los elementos constitutivos y su carga simbólicoconceptual. Una segunda parte fotográfica, que sirve de sustento a todo el material textual, a base de imágenes monocromáticas y policromáticas del estado real del vitral; y una tercera parte gráfica, donde se muestran las representaciones resultantes del levantamiento y relevamiento arquitectónico que se complementa con el analisis de geometrias existentes, tanto material en tres niveles planimétrico, altimétrico y tridimensional (tipos de materiales, colores, estructuras, técnicas de construcción) como inmaterial (historia, origen, función, estilos y carga simbólica).

\section{RESULTADOS Y DISCUSIÓN}

Partiendo del concepto de la luz, como componente fundamental en el arte vitral. Se admite, para ello, el planteamiento hecho por Campo (1998) al pensar que la luz es un componente esencial, es materia y material, cuantificable y calificable, controlable, con luz la arquitectura se hace visible, y da razón del tiempo. No obstante Barbero, Vallmitjana, \& Carreras (2015), sugieren que, bajo la contemplación de la humanidad, la luz supera su propia esencia física, para convertirse en objeto de la cultura.

En particular, el vitral de San José, está compuesto por varios conjuntos que conforman un solo panel en forma de medallón circular, con una figura especial en el centro. La complejidad de este vitral se da por cuanto su dimensión registra sobre $3.25 \mathrm{~m}$. de diámetro conteniendo 25 secciones que le dan rigidez a los conjuntos de vidrio. 
Además, la disposición del panel es consecuente con el estilo Neorenacentista, de la cual la Catedral de San José presenta su caracterización, según lo advertido por Vergel, Delgado \& Díaz (2019). Al respecto Pérgolis \& Villar (2015) definen la arquitectura del siglo XIX en Colombia, con elementos y códigos propios del neoclásico, neogótico, grecorromano entre otros, acreditándolo al eclecticismo. De ahí su esquema basilical conformado por tres naves que expresan la direccionalidad de la entrada al altar, esquema compositivo frecuente en la arquitectura sagrada. En este caso, la nave central está dotada por el vitral de San José, justo encima de la entrada. Debido a la diferencia de alturas entre el rosetón en la cara externa y el vano donde se ubica el vitral internamente, su iluminación no resulta homogénea y parte de la composición del vitral queda opaca tras el fenómeno no concéntrico de sus círculos (Figura 1). Este fenómeno se ve relacionado con los diferentes tiempos constructivos (Vergel; Delgado, y Díaz 2019), ya que el vitral interior, fue instalado tiempo antes al rosetón externo en piedra que se visualiza en fachada. De todas formas, la cuantía artística y simbólica del vitral es única, con valor en sí mismo y para la arquitectura sagrada de la Catedral.

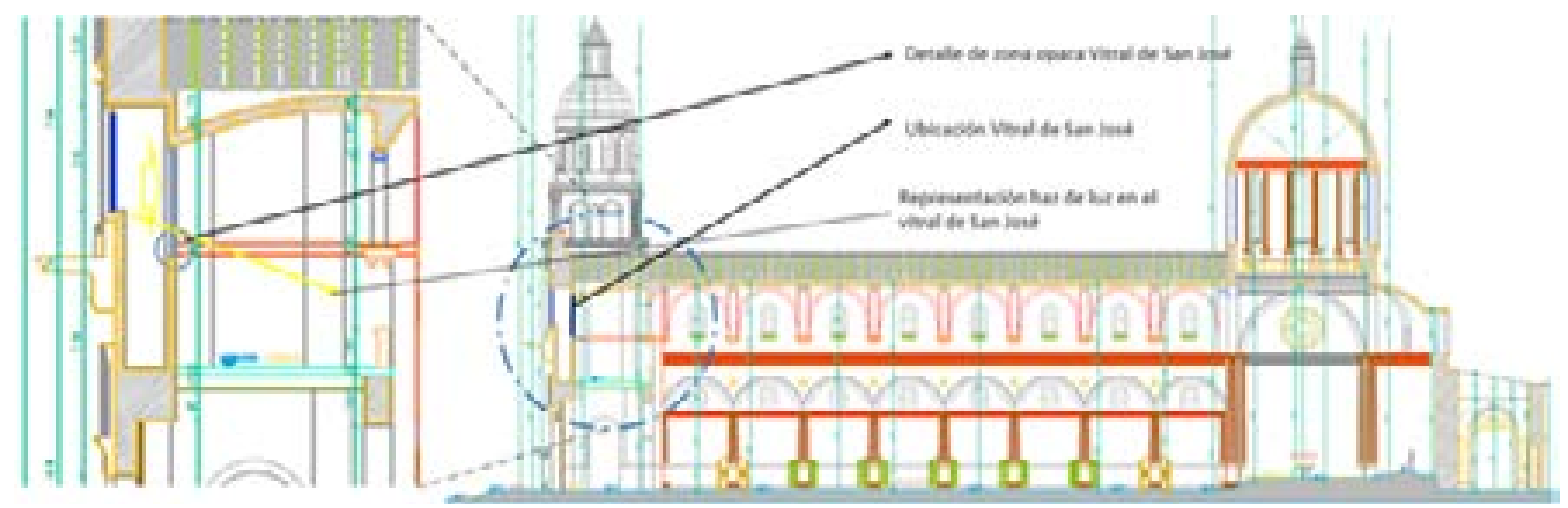

Figura 1. Ubicación arquitectónica Vitral de San Jose.Detalle ampliado señalando zona opaca y desfase de las envolventes de la fachada principal. Sección longitudinal del templo con la ubicación arquitectónica del Vitral de San Jose. Fuente: Autores.

Asuvez, en coherencia con la sección longitudinal del templo, la configuración arquitectónica en cruz latina, revela el lugar privilegiado de este vitral. Así, la nave central posee 16 vitrales que enmarca la direccionalidad al altar, acentuadas por otras 16 vidrieras distribuidas en ocho vitrales por cada nave lateral. De modo que el vitral de San José, justo en la entrada, señala el inicio del pasaje a altar, y lo que significa metafóricamente el camino a la santidad como lo refiere Díaz (2019) (Figura 2). 

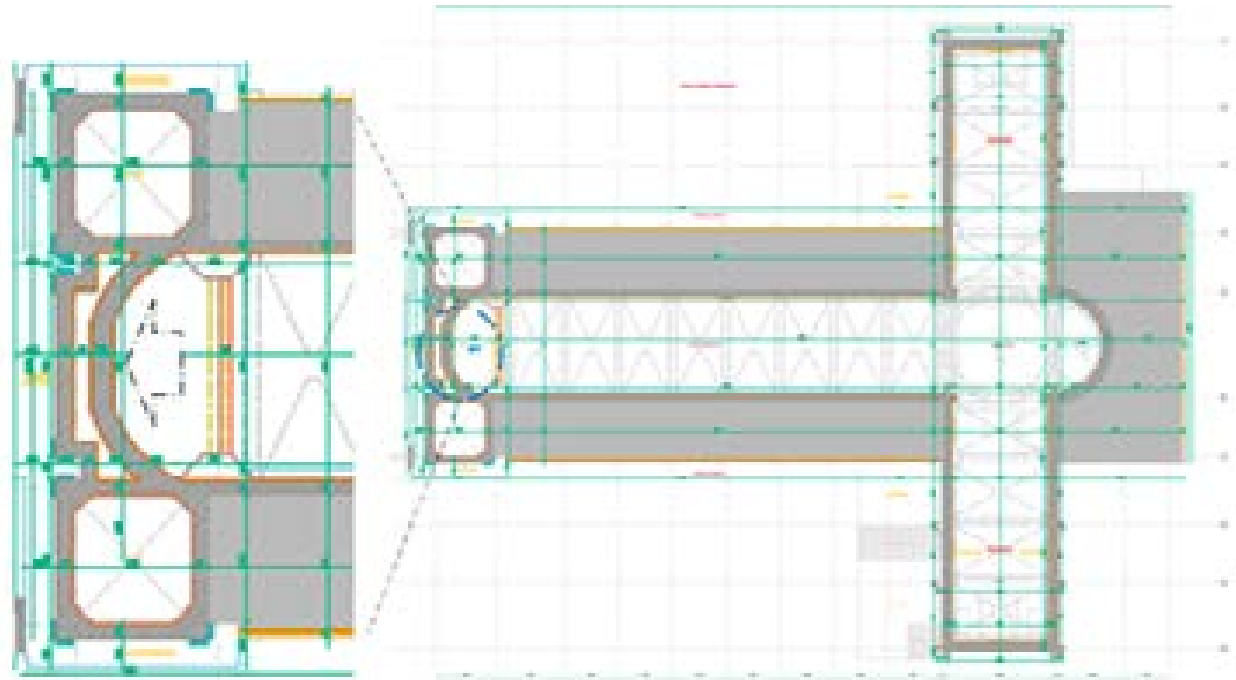

Figura 2. Ubicación arquitectónica Vitral de San Jose. Detalle ampliado en planta, zona del coro y entrada principal, señalando la ubicación del vitral de San Jose. Planta arquitectónica del templo con la localización general del Vitral de San Jose. Elaboración propia.

Todas estas observaciones arquitectónicas se complementan, con el valor artístico ya que se revela la autoría con la vidriera Mauméjean, una de las fábricas de arte decorativo más importantes de Europa. Marquina (2010) relata que la empresa Mauméjean tiene sus orígenes en Francia en 1860, en la que participan inicialmente la familia Mauméjean y posteriormente sus descendientes. Luego en 1897 se funda una de tantas filiales ubicada Madrid, España, pero hasta el año 1923 quedó constituida como Mauméjean Hnos S.A. dato relevante expuesto por Piqueras (2013), ya que de allí se puede estimar, que los vitrales de la catedral de San José de Cúcuta son posteriores a esta fecha.

Es significativo referenciar el origen de manufactura de los vitrales, puesto que esta prestigiosa empresa ganadora de varios premios internacionales como Legión de Honor de la Exposition Internationale des Arts Décoratifs et Industriels Modernes de París, en 1925, Medalla de Oro en la Sesquicentennial Exposition de Filadelfia, en 1926, Medalla de Oro en la Feria de Milán, en 1927 Gran Premio de la Exposición Iberoamericana de Sevilla, entre otros, declarados por la Sociedad Mauméjean (2010), respaldan la calidad de la obra. La creatividad artística expuesta en más de un centenar de encargos en diferentes partes del mundo, en disímiles épocas, por lo que su capacidad de ajustarse artísticamente a los requerimientos arquitectónicos, constituyen soporte de marca, estilo y presupuesto del vitral San José. En el caso de la catedral, los vitrales están elaborados bajo la práctica de corte y armado con el uso de grisalla y vidrios con color de masa, acorde a técnicas referidas por Porfirio (2018) asocaidas a la técnica tradicional, caracteriaticas impresas en obras reconocidas internacionalmente por esta firma como la estación de Toledo, parroquia Nuestra Señora de Lourdes, Morbihar Francia, y en Colombia todas las vidrieras de la Santa iglesia magistral en Bogotá

Antes del análisis iconográfico, es de destacar el mensaje implícito de los vitrales por su fuerte componente simbólico relacionado con mensaje que transmite la luz a través de los cristales de colores, como objeto pedagógico en términos religiosos, Vallespin, A., Hernández, L. \& Cervero, N. (2015) apunta que el lenguaje simbólico de la luz tiene un doble sentido, por 
un lado como difusión de la palabra de Dios a través de las imágenes luminosas dibujadas sobre las vidrieras y por otro, como transmisión de la idea de la luz como representación de lo sagrado. Por su parte Porfirio (2018) reflexiona sobre el papa Gregorio el grande, en el siglo XV, cuando señalaba el papel del icono cristiano como la "imagen es la escritura de los iletrados" de ahí su entendimiento como conocimiento, esto confirma el papel pedagógico y al mismo tiempo alegórico, donde prevalece la exaltación de la luz entendida como lo divino.

El segundo aspecto relacionado con el análisis iconográfico, debe advertir, que la imagen de San José se instituye como muestra paradigmática del perfeccionamiento emblemático, observado por De arriba (2013), pues pasa de ser una figura prácticamente ignorada en los primeros siglos cristianos a declararse patrono de la Iglesia Universal. Al respecto Conde (2012) dice que, a partir del siglo XV, se observa cambios notables, pues varia la percepción de San José como un hombre entrado en años, ubicado junto a la Virgen María, como un simple espectador, evolucionando en este vitral a una figura paternal más joven, que participa activamente con el cuidado del Niño Jesús. En este fenómeno De arriba, (2013), alude el año 1480, como fecha clave, cuando se ratificó, el 19 de marzo, como fiesta de rito simple dedicado a la devoción de San José por parte de Sixto IV.

Un aspecto, así mismo trascendental, es el acopio de las fuentes escritas sobre Jesús en el lapso de su infancia, que proporcionan datos de gran interés para el estudio iconográfico. Se parte de los Evangelios Canónicos, San Mateo y San Lucas, fuentes principales de la vida del santo, no obstante, estos pasajes breves que han conducido a una serie de autores a recrear en la pintura, escultura, vitrales y otras expresiones del arte cristiano, de modo exponencial, llegando a 1870, cuando Pío IX, lo proclama Patrono de la Iglesia Universal (De arriba 2013). Por su parte, Conde (2012), amplia la reseña, mostrando a San José, como modelo ejemplar por las órdenes monásticas. Así mismo este autor, responsabiliza a Santa Teresa, por promover su grandeza y dignidad universal.

Esta devoción a San José confluye, con el patronato de la catedral de Cúcuta, así pues, el vitral mayor, con la figura de este santo, domina la centralidad de la composición, mostrándolo de medio cuerpo, con su hijo Jesús alzado en su brazo. La proximidad de ambos rostros, expresa la ternura de su paternidad, y la similitud de sus expresiones, hacen parecer que en realidad son padre e hijo. Sostiene en su otra mano las azucenas, símbolo de pureza de corazón y de inocencia del espíritu. San José en este caso, se presenta como un hombre joven, sustentado en el detalle de sus cabellos pelirrojos, conforme a su barba. Vestido con amplia y sencilla túnica, deja ver sus manos, que paradójicamente revelan más edad que su rostro, sugiriendo el trajín de su oficio como carpintero. En su cabeza se destaca el nimbo, una aureola redonda similar a la de la Virgen Maria. Por otra parte, el Niño Jesús aparece semidesnudo, con sus manos relajadas a sus costados, revelando su figura infantil, con ello la necesidad de amparo paternal (Figura 3). 

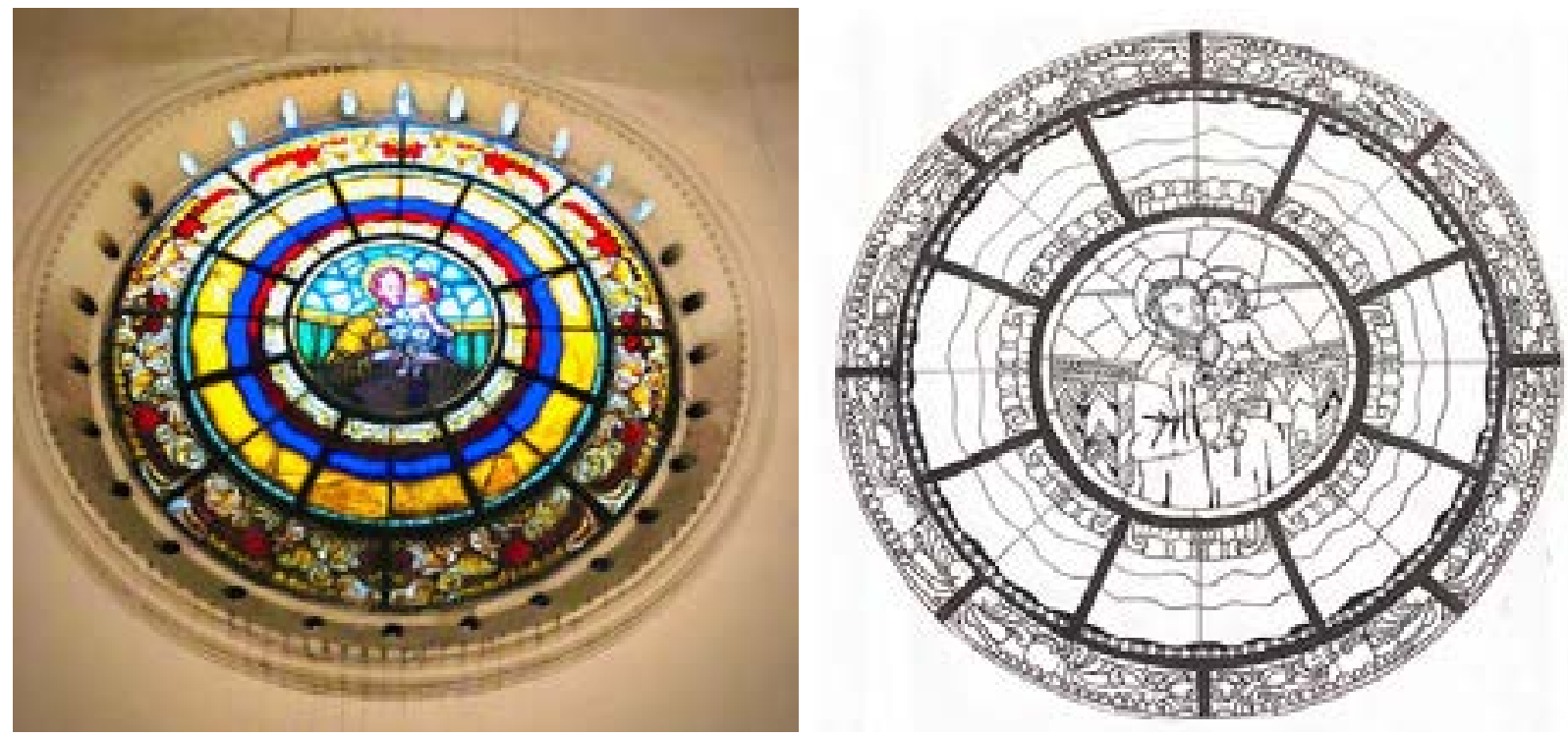

Figura 3a. Detalle del panel. Fuente: Autores. Figura 3b. Juego compositivo del vitral de San José en fotografía y en croquis. Fuente croquis: Manuela Chávez Diaz.

Esta descripción lleva consigo varios elementos fundamentales, entre ellos destacar, el proceso de santificación de José, y su misión paternal. Dado que, el proceso de santificación de José, tiene su reflejo iconográfico en el detalle del nimbo que orna su cabeza, es de denotar, como a medida del transcurso del tiempo, entendiendo que el culto generalizado a San José es mucho más tardío, la imagen del San José nimbado, se empieza a representar con frecuencia en el arte gótico, y con mayor razón, debido al aumento de su devoción, en la modernidad, justo el periodo histórico de la manufactura de este vitral.

En esta confluencia, artística y devocional, dicha aureola, semejante a la de la Virgen Maria en sus múltiples grafías, también actualiza la imagen de José, de un hombre anciano a uno joven, tal como se había descrito anteriormente. Para Moreno (2014) esta forma viril responde a su condición y consentimiento esponsal, de tal forma, que se comprende la relación matrimonial entre Maria y José, en una unión poderosa, esencialmente igualitaria, es decir "hace iguales a los desiguales" en "una sola alma y un solo corazón" (pág. 282). Este análisis se apropia de lo que significó para José el consentimiento esponsal, ya que no rompió con la promesa de matrimonio entre él y Maria, por el contrario, favorece sin duda el plan de Dios para desposar a Maria, y unirse a ella sin ningún reproche, servirle y amarle.

Por otra parte, el cambio iconográfico a través del tiempo, revelando estas coyunturas a su devoción, lo reinterpretan como un hombre comprometido con su misión paternal, de ahí Moreno (2014) lo conceptualiza como un servidor: su potestad radica en su servicio a Jesús, en su disponibilidad para guiar la familia, a instrucción del Angel San Miguel. En consecuencia, su autoridad y capacidad, la pone al servicio de los suyos. Tanto Moreno (2014) como Conde (2012) coinciden en vincular las virtudes humanas de Jesús y su oficio, con la vocación de San José para enseñarle. Esta fuente de identidad, Moreno (2014) la desarrolla, para proponer el vínculo consanguíneo, como irrelevante: "al final, José y su Hijo se parecían incluso físicamente", tal como se manifiesta en el vitral de la catedral, "José es 'realmente padre. En José se refleja todo el poderío de la gracia, de la vida divina en el hombre" (Moreno 2014, pág. 283). 
Luego, el vitral se configura de manera concéntrica, San José como patrono de la catedral y punto focal de la composición en un área de $1.01 \mathrm{~m}^{2}$, le complementa una bandera de Colombia, en $2.4 \mathrm{~m}^{2}$ de área, constituido por 16 unidades de trapecios circulares de $0.15 \mathrm{~m}^{2}$ cada uno, en el contorno medio del vitral orientados en forma centrada. Los efectos cromáticos dados por el predominio de los colores claros, azules, rojos, marrones, naranjas, verdes y amarillos, conforman un interesante ambiente tornadizo con referencia de la posición del sol. Las dos figuras están expresadas frontalmente con efectos de sombra, que da la impresión de relieve, se ajustan a características de tipo nórdico, por su esbeltez, rasgos refinados, piel blanca, manos delgadas, se enmarcan en cenefas, así mismo se usan grafías de capiteles, iconografías domésticas como un telón verde a la espalda de San José y el niño, de tal manera que expresan lazos estilísticos con el inicio de la modernidad, un arte ecléctico acorde a la arquitectura de la catedral.

En definitiva, el análisis geométrico, describe un panel circular de 3.25 metros de diámetro que incluye vidrios y estructura interna, el cual se modula en 25 conjuntos de piezas cuya composición se hace a partir de tres circunferencias concéntricas. La primera circunferencia está marcada con el círculo central de radio $0.57 \mathrm{~m}$, luego le siguen dos coronas circulares, una conformada con 16 trapecios circulares dispuestos con ángulo central de $22.5^{\circ}$ y la otra con 8 trapecios circulares a $45^{\circ}$, consolidando una superficie total del panel de $8.3 \mathrm{~m}^{2}$ que incluye la estructura interna y $6.22 \mathrm{~m}^{2}$ de área en vidrio (Figura 4 y 5 ).

\begin{tabular}{|c|c|c|c|c|c|c|}
\hline NOMBRE & $\begin{array}{l}\text { IMAGEN } \\
\text { INTERIOR }\end{array}$ & $\begin{array}{l}\text { IMAGEN } \\
\text { EXTERIOR }\end{array}$ & PLANO & Diámetro & $\begin{array}{c}\text { No de } \\
\text { secciones }\end{array}$ & $\begin{array}{c}\text { Angulo } \\
\text { del } \\
\text { sector } \\
\text { circular }\end{array}$ \\
\hline $\begin{array}{l}\text { San } \\
\text { José }\end{array}$ & $m=$ & 828 & & $3,25 \mathrm{~m}$ & 25 und. & $22,5^{\circ}$ \\
\hline
\end{tabular}

Figura 4. Imagen de vitral, fachada externa y datos geométricos generales del vitral de San Jose. Elaboración propia. 


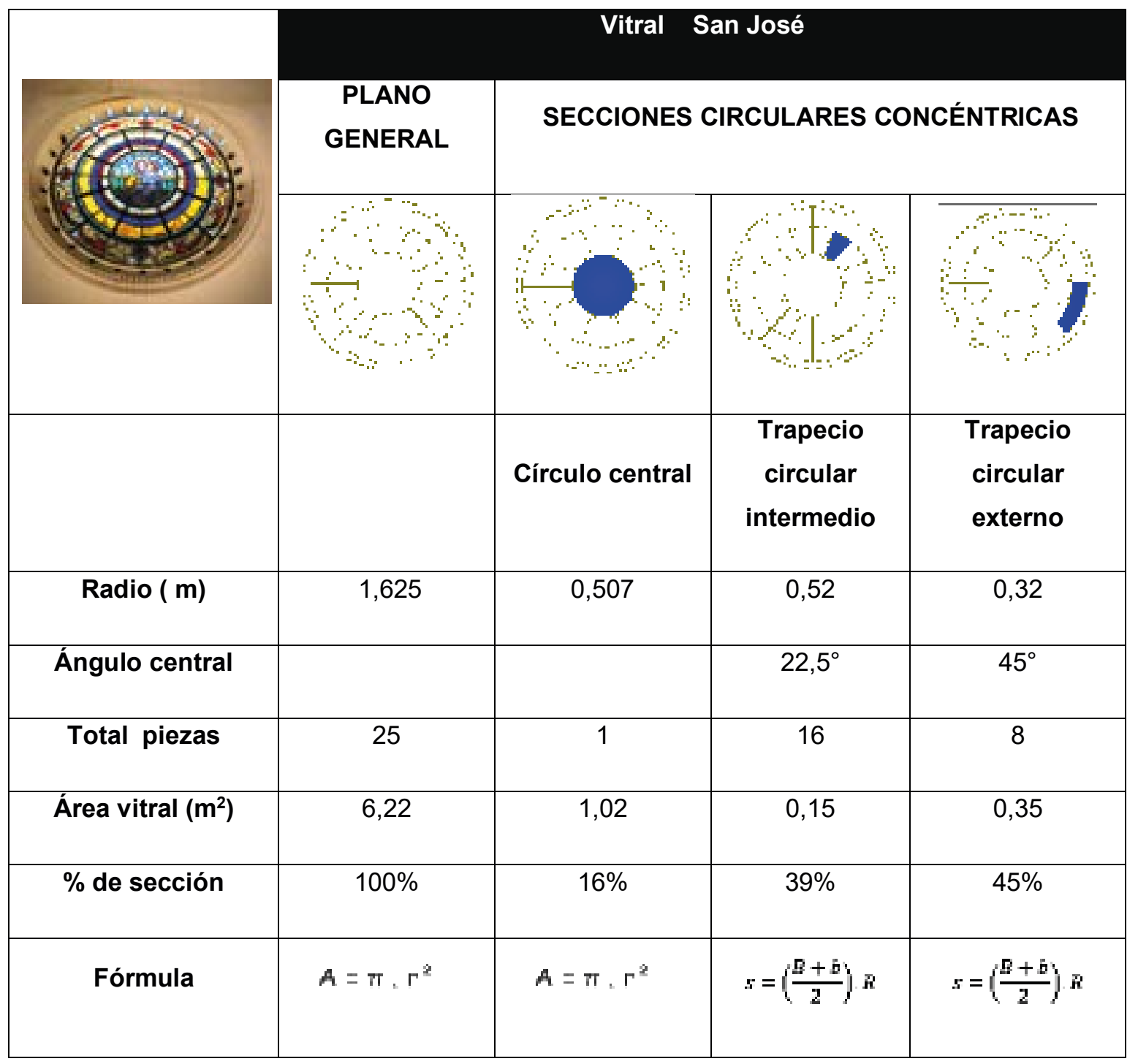

Figura 5. Imagen, con datos de radio, ángulo central, total de piezas y formula de cada una de sus partes del vitral de San José. Fuente: Autores

Al analizar la realidad constructiva de la fachada de la Catedral San José, parece confirmar históricamente, que el vitral interior fue instalado tiempo antes al rosetón circular exterior en piedra que se visualiza en fachada. Por consiguiente, se advierte geométricamente este fenómeno constructivo de círculos no concéntricos, ya que la instalación del rosetón externo en piedra se hace a $12.64 \mathrm{~m}$ del nivel del suelo, mientras el vitral en vidrio en la cara interna del templo se desarrolla a $10.74 \mathrm{~m}$ del mismo nivel, lo que genera una sombra interna llamada lúnula con sus centros desfasados en $1.90 \mathrm{~m}$ uno del otro, tal como se había descrito en el análisis arquitectónico. Así, dicha sombra que aparece entre los rosetones representa un área de lúnula de $5.8 \mathrm{~m}^{2}$ y perímetro de $10.3 \mathrm{~m}$ sin luminiscencia (Ver figura 6). Se considera así, la luz como un componente esencial, cuantificable y calificable en la caracterización geométrica del vitral de San José. 


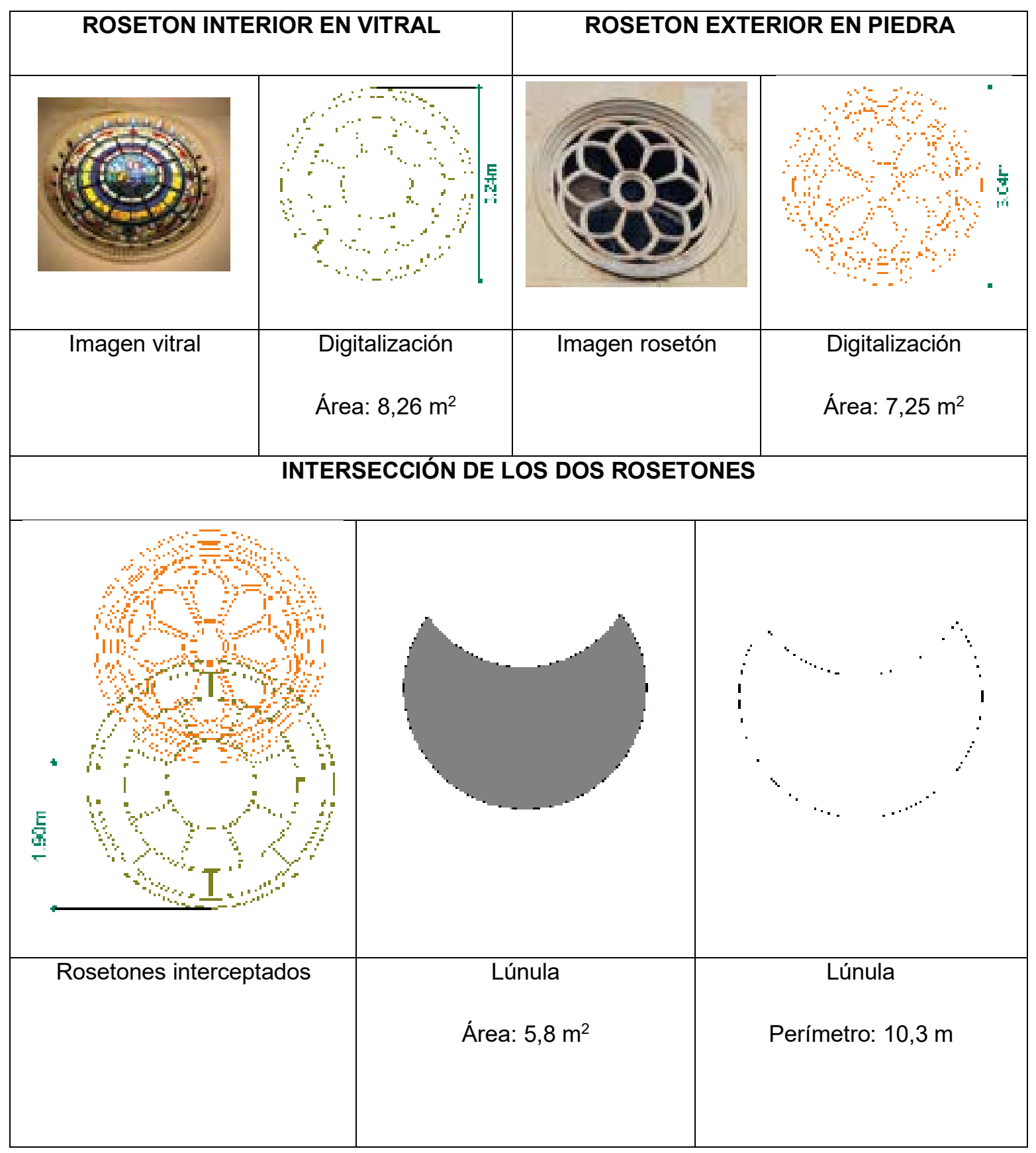

Figura 6. Imagen, secciones circulares no concéntricas secciones concéntricas, lúnula del vitral.

\section{Fuente: Autores}

\section{SÍMBOLOS Y NÚMEROS}

Como valores simbólicos importantes de todos los órdenes en su conjunto, se tienen los números cinco, tres, dos, ocho, cuatro, diesciseis, 29. El roseton le conforma dos rosas que surgen del cruce de cuatro ojivas, conformando cuatro ejes simétricos asociados a la intersección de un meridiano y un paralelo divide la tierra en cuatro sectores, de igual manera la aureola de San José lo conforman cuatro segmentos de corona circular que representan al número de la creación, norte, sur este y oeste. Cuatro vinculado religiosamente a la cruz, utilizado para significar lo sólido, lo tangible, lo sensible. Su 
relación con la cruz lo convirtió en un símbolo incomparable de plenitud, de universalidad, un símbolo de totalización, cuatro es el número del cuerpo, (Biedermann, 2004, p. 425). Hay cuatro últimas cosas del cristianismo, a saber, los cuatro hechos escatológicos de la teología cristiana: la muerte, el juicio, el cielo y el infierno (Feuerstein, 2001, p. 76). La cruz tiene cuatro brazos. El tetramorfo está compuesto por los cuatro evangelistas: San Marco, San Giovanni, San Luca y San Mateo, que corresponden simbolicamente: el león, el águila, el buey y el ángel. El número cuatro designa la plaza, lo terrenal y la totalidad de la creación y de lo revelado En los continentes, los jefes y los reyes son llamados: señores de los cuatro mares, o de los cuatro soles, o de las cuatro partes del mundo (García, 1983, Chevalier, 1982, p. 267), cuatro son las letras que forman el tetragrama del nombre de Dios (JHWH), Jahwèh (Cooper, 2012, p. 195)

El número cinco resultado de la suma del primer número par más el primer número impar $(2+$ 3). El dos se encuentra en los dos elementos humanos padre hijo, dos lírios blancos, representan la figura de María de la madre y son un simbolo de la anunciación y la resurección; dos con valor simbólico bíblico (Adán y Eva), los dos son un símbolo de toda dualidad, concepto dicotómico u oposición, número de todas las ambivalencias y duplicaciones, primera y radical de las divisiones: el bien y mal, el blanco y el negro, el masculino y el femenino, la materia y el espíritu, día y noche (Tomasini, s.f. ). 29 son las llamas que se desprenden del arco de la catedral que circunda el rosetón, simbolizando la luz del espíritu santo, 29 significa incompleto pero en éste conformado por el 2 y el 9 se tiene que $2+9=11$ y $1+1=2$. $Y$ el tres=cielo, tres tramos del vitral, es el número del alma, tres escenarios circulares que enmarcan al ser humano en las imágenes de José y Jesús, el contexto a través del símbolo patrio en la bandera de Colombia y el perímetro que enmarca los cielos. Cinco sectores circulares tiene la aureola de Jesús, cinco representa el número de órdenes que tiene la iglesia y tres los elementos en que estos se descomponen, es el número de armonía y equilibrio $\mathrm{y}$, además, es el número del centro. El cinco es también el símbolo del universo: dos ejes, uno vertical y otro horizontal que pasan por el mismo centro (Rendon, 2019). Cinco es también el número de los sentidos y el número de la fortuna (riqueza, longevidad, paz, virtud y salud); cinco quiere decir como ubicado a un nivel divino; en la esfera del intelecto, el cinco indica los espíritus superiores, las inteligencias, los ángeles, las almas de los cuerpos.

El seis se encuentra en los petalos de los lirios, el Venerable San Beda (673-735) comparó a la Santísima Virgen María con el lirio blanco, simbolizando los pétalos la pureza virginal de su cuerpo, y sus doradas anteras, el resplandor de su alma. Encontramos nuevamente referencia a la pureza de María cuando el gran San Bernardo (1090-1154) describió a Nuestra Señora como violeta de humildad, lirio de castidad, rosa de pureza. El seis representa algo incompleto. Asi mismo 6 es el número de hombre, creado el sexto dia de la creación, la rdivisión del tiempo en relación con el hombre, la hora 6 divide al dia, en la hora 6 murió jesús en la Cruz, el 6 es mencionado 199 veces en la Biblia.

En la catedral San José el número más representativo es el 8, y no podría estar ausente en el vitral de San José, el 8 está intimamente ligado a Jesús, Cristo resucitó el primer dia de la semana que fue el octavo, significa fertilidad abundante, expresa el comienzo, el primer dia de la nueva vida, lo nuevo, la biblia contiene 8 resurrecciones, incluyendo la de los santos, 8 personas iniciaron la segunda humanidad siendo Noe sus 3 hijos y sus esposas, la fiesta de los tabernáculos duraba 8 dias, existen 8 cantos que se guardan para ser cantandos despues de la resurrección; Aaron y sus hijos fueron consagrados en 7 dias y comenzaron su misión 
en el dia octavo, y en el roseton se encuentra en las divisiones de los trapecios circulares que lo conforman el cual es múltiplo de 8 , por esto son 16 fracciones en la primera corona circular de vidrios que representan la bandera nacional y 8 en la última corona con motivos orgánicos, simbolizando olvidar aquello que se dejó atrás y el comienzo de una nueva era llena de ilusión, el momento del inicio.

Finalmente se tiene el dieciseis, $1+6=7$ y 7 es el número de la plenitud marcada por Dios. En el vitral, la primera corona se divide en 16 fracciones de trapecios circulares de $22.5^{\circ}$ conformado de 2 y 5, 2+5=7. Es la perfección sobre la perfección. El señor le dice a Pedro hasta 70 veces 7 , el 7 se cita 737 veces en la Biblia, 7 copas, 7 sellos, 7 trompetas que recuerdan que la catedral fue afectada por el terremoto de Cúcuta en 1875, pero que dada la fe del pueblo que habita a san José de Cúcuta, este templo resurge en estos años setenta.
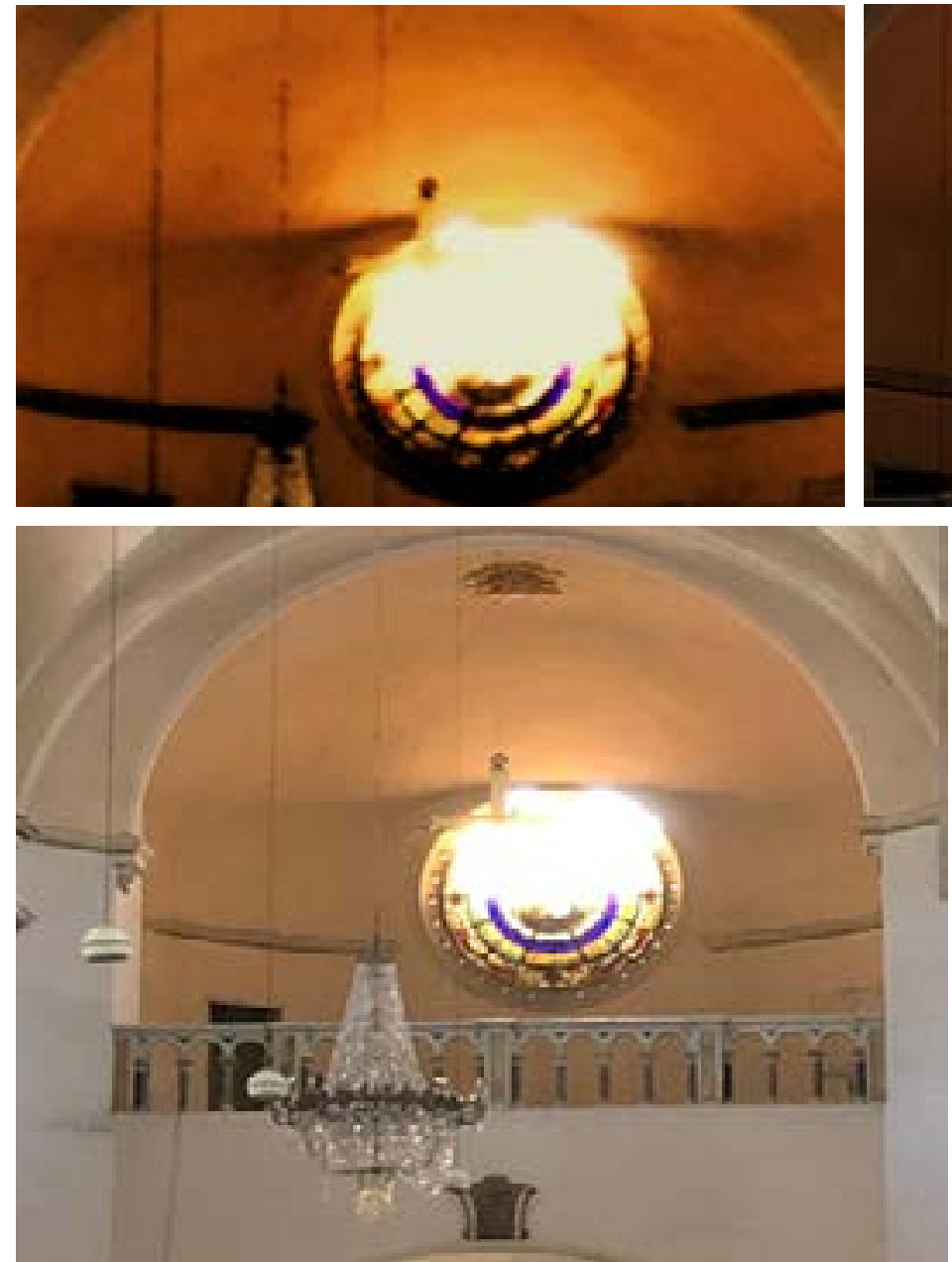

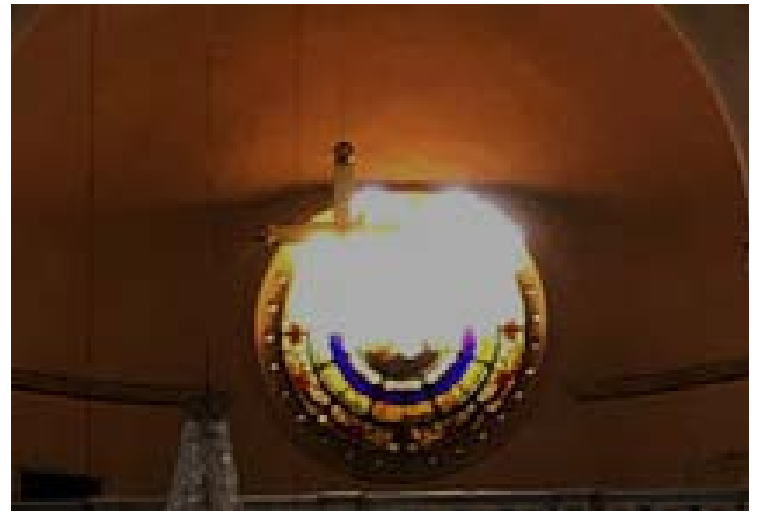

Figura 7.

Imagen de vitral y luz en coro que ilumina la cruz.

Fuente: Autores.
La misión del roseton y su asociación al vitral consiste en iluminar el interior del templo y conseguir ambientes misteriosos al incidir los rayos multicolores filtrados por las vidrieras sobre determinadas partes. En el vitral de San José, La luz del sol naciente al atravesar el rosetón más grande se proyecta en la cruz de enfrente (Figura 7). Y siendo las tres de la tarde, el sol irradia sobre el vitral provocando un fenomeno cuyo reflejo simula un eclipse, los autores lo asociamos al eclipse de crucifixión o presagio. Alli se torna la imagen del dia y la 
noche, la luz y la oscuridad, su mayor incidencia en el crucifijo a esta hora señala la resurreción y la luna fruto de la sombra y el no paso de luz en la parte inferior del vitral por la diferencia en posicionamiento con la roseta externa, muestra la penumbra, mientras en el techo el resplandor enrojecido producto del reflejo de la roseta exterior señala el camino al cielo. La explicación es científica: la catedral está orientada de este a oste en su corte longitudinal de forma que la luz en el ponente del sol atraviesa simultáneamente el rosetón en fachada de la Catedral y por ende permea la luz en la parte superior del vitral interior de San José, siendo las tres de la tarde cuando alcanza su mayor incidencia. En el transcurrir del día la dirección del sol permite observar un movimiento de la luz interior dirigido hacia arriba, opuesto a la natural dirección de la gravedad, al estar la parte superior del vitral orientada hacia el exterior de la catedral. Al observar el fenómeno y dejarse sumergir en la luz, se excluyen las masas generando una sensación de espacio libre irreprimido.

\section{CONCLUSIÓN}

El vitral de San José, ubicado en la nave central, fachada principal dando su cara visible al coro de la Catedral, está compuesto por varios conjuntos que conforman un solo panel en forma de medallón circular, entre ellos, las figuras del centro, Jose y el niño Jesús dominando toda la composición. La complejidad de este vitral se da por cuanto su dimensión registra $3.25 \mathrm{~m}$ de diámetro, conteniendo 25 secciones que le dan rigidez al panel. La ubicación del vitral en la nave central, demuestra no solo su condición jerárquica en el conjunto de vitrales, sino también su protagonismo mostrando simbólicamente el camino al altar.

Es evidente el patronato de la catedral, dedicando el vitral mayor, a San José, al considerar esta imagen protagónica en la centralidad de la composición, conformada también por la bandera de Colombia como símbolo patrio. El análisis iconográfico presenta una figura pictórica coherente con el tiempo de ejecución del vitral, datándolo de 1923 por lo que la influencia moderna es evidente al mostrar un José más joven, más activo de su papel paternal y su compromiso familiar. Partiendo de la idea, de que el culto generalizado a San José es tardío, no cabe duda que, en la representación de José, en la catedral, se da equiparando la orna, con la aureola de la Virgen María en sus múltiples perfiles, de ahí la representación de su poderío espiritual, logrado en la modernidad. Con referencia al análisis geométrico, el área total del panel en forma de rosetón es de 8.3 $\mathrm{m}^{2}$. Se advierte el fenómeno de círculos no concéntricos, ya que la instalación del rosetón externo no coincide con el círculo del vitral en la cara interna del templo, en consecuencia, aparece el área denominada lúnula que corresponde a un área de $5,8 \mathrm{~m}^{2}$, generado opacidad en una porción del panel.

\section{REFERENCIAS BIBLIOGRÁFICAS}

Barbero, S; Vallmitjana, S. \& Carreras, C. (2015). Historia de las concepciones científicas sobre la luz. ARBOR Ciencia, Pensamiento y Cultura Vol. 191-775, septiembre-octubre. Visto en: http://arbor.revistas.csic.es

Blondel, N.; Callias, M. y Chaussée, V. (1986). "Le vitrail archéologique: fidélité ou trahison du Moyen Age?". En: Annales de Bretagne et des pays de l'Ouest, t. 93, n. $^{\circ} 4$, Le vitrail au XIXe siècle, pp. 377-381.

Campo, B. (1998). La idea construida la arquitectura a la luz de las palabras. Textos Dispersos Colegio Oficial de arquitectos de Madrid (coam). España. 
Conde, M. (2012). La figura de San José en el arte gótico alavés. PREMIOS DE INVESTIGACIÓN UNIVERSITARIA. Sancho el Sabio, 35, 2012, 263-291 visto en file:///C:I Users/ufps/Downloads/Dialnet-LaFiguraDeSan JoseEnEIArteGoticoAlaves-4096161\%20(2).pdf

Cooper, J. Off camera, p.290

Chevalier, R.A, (1982). ApJ 420

De arriba, S. (2013). San Jose. Revista Digital de Iconografía Medieval, vol. V, $n^{0}$ 10, 2013, pp. 57-76. Visto en: https://www.ucm.es/data/ cont/docs/621-2013-12-14-07.\%20San $\% 20$ Jos\%C3\%A9.pdf

De fusco, R. (1.981): "Historia de la arquitectura contemporánea". Celeste ediciones. Madrid.

Delgado, A., Díaz, Y. \& Vergel, M. (2.018). El paisaje Arquitectónico y sonoro del campanario de la Catedral de San José de Cúcuta. Revista Logos Ciencia \& Tecnología.vol.11 N 1, enero marzo 2.019 P52-60v

Díaz, Y. (2019). La arquitectura sagrada en San José de Cúcuta (I Parte): Caso de estudio, Iglesia de Nuestra Señora de la Candelaria. Trabajo investigativo presentado para el escalafón docente. UFPS, Cúcuta, Colombia.

Díaz-Umaña Y, Vergel-Ortega M, Delgado-Rojas JA. Modelo geométrico y arquitectónico de la cúpula mayor en San José de Cúcuta. bol.redipe [Internet]. 1 de marzo de 2020 [citado 25 de abril de 2020];9(3):160-6. Disponible en: https:// revista.redipe.org/index.php/1/article/view/941,

Díaz, Y; Vergel, M. y Delgado, J. (2020). Modelo geométrico y arquitectónico de la cúpula mayor en San José de Cúcuta. Revista boletín Redipe 9 (3):160-166 marzo 2020 [En línea]: https:// www.researchgate.net/publication/340362293 Modelo geometrico y arquitectonico de la cupula mayor en San Jose de Cucuta
García Atienza, J. (1983). En busca de la historia perdida. Martínez Roca.

Marquina, E. (2010). José y Enrique Mauméjean Lalanne. Revista del Casino de Madrid Nuestra Historia. Gaceta sobre la historia, los socios, los acontecimientos, la vida social, las anécdotas, el edificio, las actividades ... Visto en : pg.2246. http://www.casinodemadrid.es/sp/revista/ Revista61/PDF/22-32\%20NH\%20Socio $\% 20$ ilustre.pdf

Moreno, A. (2014). La devoción a San José ¿un nuevo modelo de virilidad? el caso de España. siglosXValXVIII.CAURIENSIA, Vol.IX(2014)245285. Visto en : http://dehesa.unex.es/bitstream/ handle/10662/3809/1886-4945_9_245. pdf?sequence $=1$ \&isAllowed $=y$

Pérgolis, J \& Villar, M. (2.015). Arquidiócesis, arquitectura y espíritu del tiempo entre la representación y la significación. Arquidiócesis de Bogotá 450 años: miradas sobre su historia. Arquidiócesis y Universidad Santo Tomas.

Piqueras, R. (2.013). La anunciación. Una vidriera de la casa Mauméjean en Almansa(Albacete). Instituto de Estudios Albacetenses. Visto en: https://dialnet.unirioja. es/servlet/autor?codigo $=792770$

Pimentel, J. (2015). Teorías de la luz y el color en la época de las Luces. De Newton a Goethe". Arbor, 191 (775): a 264. Visto en http://dx.doi. org/10.3989/arbor.2015.775n5003

Porfirio, S (2.018). El arte vitral. Aspectos técnicos en tiempos históricos específicos y aportes contextuales desde su circuito de producción. Universidad Nacional de la plata facultad de bellas artes. Tesis de grado. Visto en: http://sedici.unlp.edu.ar/bitstream/ handle/10915/71154/Documento_completo. pdf? sequence $=1$ \&isAllowed $=y$

Rendón Gómez, Á. (2019). El Plano

Oculto (Safe Creative ed.). 
Sociedad Mauméjean (2.010). Casa Mauméjean de vidrieras artísticas. Pag.web empresarial visto en: http://www.vidrierasmaumejean.com/ es-vidrieras-maumejean-s-l-clientes.html

Tomasini, M. (s.f.). El número y lo sagrado en el arte. Obtenido de Universidad de Palermo: https://www.palermo.edu/ingenieria/downloads/ CyT\%204/CYT406.pdf

Vallespin, A., Hernández, L. \& Cervero, N. (2.015). El espacio Gótico según Hans Jantzen y la evolución de las vidrieras. Universidad Politécnica de Valencia. Visto en: https://doi. org/10.4995/ega.2015.3671

Vergel, M; Delgado, J \& Díaz, Y. (2019). Cathedral bell's San José de Cúcuta: Heritage and acoustics. XIV Applied Mathematics Meeting and XI Statistics Meeting, IOP Conf. Series: Journal of Physics: Conf. Series 1329 (2019) visto en: https://iopscience.iop.org/ article/10.1088/1742-6596/1329/1/012004/pdf 